Check for updates

Cite this: RSC Adv., 2019, 9, 22355

Received 4th June 2019

Accepted 4th July 2019

DOI: $10.1039 / c 9 r a 04211 c$

rsc.li/rsc-advances

\section{Submicron fibers as a morphological improvement of amorphous zirconium oxide particles and their utilization in antimonate $(\mathrm{Sb}(\mathrm{v}))$ removal $\uparrow$}

\author{
Satu Lönnrot, (DD* Valtteri Suorsa, (D) Johanna Paajanen, Timo Hatanpää, \\ Mikko Ritala and Risto Koivula iD
}

\begin{abstract}
Mesoporous and large surface area zirconium oxide aggregate granules with good adsorption properties were synthesized using a simple precipitation method. Since utilization of these small and fragile particles is considered rather difficult in larger scale column operation, the product was formed into a fibrous form to improve its usability. The submicron fibers were obtained from an optimized electroblowing synthesis that resulted in elastic and uniform fibers with a tetragonal structure and high length-to-diameter ratio. In antimonate $(\mathrm{Sb}(\mathrm{v}))$ adsorption experiments, the higher calcination temperature $\left(350^{\circ} \mathrm{C}\right)$ of the fibers did not seem to decrease the $\mathrm{Sb}(\mathrm{v})$ adsorption capacity excessively since the high theoretical adsorption capacities were $113 \mathrm{mg} \mathrm{g}^{-1}$ and $58 \mathrm{mg} \mathrm{g}^{-1}$ for the aggregate and fibers, respectively. Both materials had fast kinetics, fibers being faster in the beginning of the reaction. Moreover, both materials offered efficient $\mathrm{Sb}(\mathrm{v})$ removal in the studied $\mathrm{pH}$ range from 1 to 11 by reaching over $99.9 \%$ adsorption in the optimal $\mathrm{pH}$ range. X-ray absorption near edge spectroscopy (XANES) revealed that $\mathrm{Sb}(\mathrm{V})$ stays as pentavalent antimony after being adsorbed by these materials and based on the isoelectric point shifts in the zeta potential measurement, adsorption occurs mainly by an innersphere complexation reaction. Finally, our study showed that pressure buildup in a flow-through column packed with zirconium oxide fibers was significantly lower than in a column packed with aggregates. Thus, zirconium oxide aggregates can be formed into submicron fibers with enhanced column operation properties without a too large compromise in the adsorption properties.
\end{abstract}

\section{Introduction}

Zirconium oxide is a versatile and well-studied material with multiple applications, including as catalysts, gas sensors, ceramics and fuel cells. ${ }^{1-4}$ Zirconium oxide can be synthesized in amorphous, cubic, tetragonal and monoclinic forms, the stability and occurrence of which depend on crystallite size, dopants, synthesis $\mathrm{pH}$ and temperature.$^{5-7}$ Monoclinic zirconium oxide is found to be stable below $1170{ }^{\circ} \mathrm{C}$ and cubic above $2370{ }^{\circ} \mathrm{C}$ whereas temperatures between $1170{ }^{\circ} \mathrm{C}$ and $2370{ }^{\circ} \mathrm{C}$ stabilize the tetragonal form. ${ }^{8}$ The tetragonal zirconium oxide can however exist at room temperature in a metastable state that can be achieved for instance by limiting the crystal size to below $30 \mathrm{~nm} .{ }^{9}$ In ceramics, the tetragonal structure is often preferred due to its superior mechanical properties such as fracture toughness, and strength. ${ }^{10}$

In addition to different crystal structures, zirconium oxide can be prepared in different morphologies, such as nanopowders, microspheres, grains, films and fibers. ${ }^{711-15}$ One method to

Department of Chemistry, FI-00014 University of Helsinki, P. O. box 55, Finland. E-mail: satu.lonnrot@helsinki.fi

$\uparrow$ Electronic supplementary information (ESI) available. See DOI: 10.1039/c9ra04211c produce nanocrystalline zirconium oxide is a precipitation method in which zirconium precursor, which is first dissolved into acid, is precipitated with base causing the formation of small colloids that can stay monodispersed or form aggregates during a drying process. ${ }^{16}$ Precipitated materials usually have a large specific surface area and porosity but the use of such small particles is rather challenging in some applications, for example, in fixed-bed columns. ${ }^{17}$ In industrial scale columns, pressure surges are breaking these fragile aggregate particles leading to column blockages and leakages of nanoparticles out of the columns. This problem could be avoided by formatting zirconium oxide into a fiber. Nano- and submicron fibers are often produced by a spinning technique including electro- and blowspinning, and eletroblowing that are applicable to the synthesis of various materials including zirconium oxide. ${ }^{\mathbf{1 8 , 1 9}}$ The electroblowing synthesis enhances the production rate of fibers compared to electrospinning since additional gas flow induces faster evaporation of solvents that enables greater solution feeding rates. ${ }^{20}$ The production rate of fibers can be further increased by adding needles to the synthesis unit. Nanofibers in general show some excellent properties such as high specific surface area and good mechanical strength, and handling of woven fiber mats is simple compared to small particles. ${ }^{\mathbf{1 4}}$ The forementioned different 
morphologies and structures have a determining impact on surface properties, such as specific surface area, porosity and pore size, which are the main factors contributing to the adsorption through available sorption sites. ${ }^{11,21}$

Contamination of toxic $\mathrm{Sb}$ in natural waters have raised concerns of its effects on human health and environment. Weathering of rock minerals, soil runoff and anthropogenic sources such as mining and smelting industries are releasing antimony into the natural waters. ${ }^{22}$ In non-polluted areas, a typical antimony concentration in water is less than $1 \mu \mathrm{g} \mathrm{L}^{-1}$ but near industrial areas the concentration can be over 100 times that of the natural level. ${ }^{22}$ Antimony is a metalloid, resembling arsenic and phosphorus, that occurs in two oxidation states: antimonite $(\mathrm{Sb}(\mathrm{III}))$ and antimonate $(\mathrm{Sb}(\mathrm{v}))$, in natural waters from which the latter is the prevalent in oxidizing conditions. In the oxidizing environment, $\mathrm{Sb}$ (III) is thermodynamically unstable, but $\mathrm{Sb}(\mathrm{v})$ have also been found from anoxic systems. ${ }^{22} \mathrm{Sb}(\mathrm{v})$ has two hydroxyl species: $\mathrm{Sb}(\mathrm{OH})_{5}$ that exists below pH 2.7 and $\mathrm{Sb}(\mathrm{OH})_{6}{ }^{-}$that is a prevalent above this $\mathrm{pH}$-value. ${ }^{23}$ This makes $\mathrm{Sb}(\mathrm{OH})_{6}{ }^{-}$a more important species from the uptake point of view. Respectively, three hydroxyl species of $\mathrm{Sb}$ (III) in the order of increasing $\mathrm{pH}$ are $\mathrm{Sb}(\mathrm{OH})_{2}{ }^{+}, \mathrm{Sb}(\mathrm{OH})_{3}$ and $\mathrm{Sb}(\mathrm{OH})_{4}{ }^{-23}$ As a more soluble and mobile species, $\mathrm{Sb}(\mathrm{v})$ was selected for this study.

Because of the hazardous nature of antimony, several authorities have set maximum concentration limits of antimony for drinking water. Commonly, the maximum level for anti-

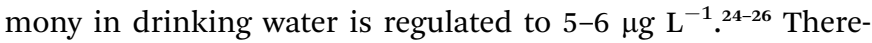
fore, several methods for separation of antimony have been suggested including coagulation, liquid extraction, membrane separation, electrochemical methods, adsorption and bioremediation. ${ }^{27-32}$ For years, antimony separation has been conducted with coagulation method that combines $\mathrm{Fe}$ or $\mathrm{Al}$ salt precipitation and adsorption. The more common Fe precipitation has effective particularly for $\mathrm{Sb}$ (III) but coexisting anions such as $\mathrm{PO}_{4}{ }^{3-}$ and $\mathrm{SO}_{4}{ }^{2-}$ are hampering already weaker separation of $\mathrm{Sb}(\mathrm{v}) .^{33}$ The removal efficiency could be improved by using selective adsorption since adsorption is a simple, efficient and inexpensive method for metal separation from water, especially on trace level concentrations. ${ }^{27}$

Some zirconium based materials such as zirconium oxide $^{12,26}$ iron-zirconium bimetal oxide, ${ }^{26}$ zirconium oxide decorated carbon nanofibers, ${ }^{\mathbf{1 4}}$ zirconium-based metal-organic framework $^{34}$ and Zr-loaded saponified orange waste ${ }^{35}$ are proven to be efficient $\mathrm{Sb}(\mathrm{v})$ adsorbents. However, most of these materials are composites or hybrids that chemical and physical properties can greatly differ from those of pure zirconium oxide. In fact, zirconium oxide possesses several excellent properties as an adsorbent. It is practically insoluble over a wide range of $\mathrm{pH}$ and is resistant to strong reducing and oxidizing conditions. Moreover, as a metal oxide, zirconium oxide should have a vast amount of surface hydroxyl groups that are proposed to strongly interact with anions. ${ }^{21,26}$ The non-toxicity of zirconium oxide further enables its applicability in antimony removal, from industrial wastewater to daily drinking water purification.

Thus, in this study, we synthesized granular zirconium oxide aggregate material by using easy and inexpensive precipitation method that is known to result in material with excellent adsorption capabilities. The morphology of the product was then improved by electroblowing zirconium oxide into submicron fibers. The electroblowing synthesis is more challenging but fibers should provide a high specific surface area indicating good adsorption capacity, and better usability in columns due to its mechanical performance. Hence, our goal is to find out, if a well-working precipitated zirconium oxide grains can be formatted into submicron fibers without losing too much of its great adsorption capabilities. Thus, $\mathrm{Sb}(\mathrm{v})$ adsorption properties of granular and fibrous zirconium oxides are compared with each other by the same author resulting a coherent comparison between materials. The main focus is to study morphology, structure and surface properties of these two materials and their influence on $\mathrm{Sb}(\mathrm{v})$ adsorption capability. Our study investigated the effect of $\mathrm{pH}$, contact time and competing ions on $\mathrm{Sb}(\mathrm{v})$ adsorption and determined the $\mathrm{Sb}(\mathrm{v})$ adsorption capacities of the materials. In addition, pressure buildups in the columns packed with fibers and aggregate grains was examined.

\section{Materials and methods}

\subsection{Chemicals}

$\mathrm{Sb}_{2} \mathrm{O}_{5}$ (99.995\% trace metal basis) was purchased from SigmaAldrich and $\mathrm{NaNO}_{3}(>99 \%)$ from VWR Chemicals. $\mathrm{NaHCO}_{3}$, $\mathrm{Na}_{2} \mathrm{SO}_{4}$ and $\mathrm{H}_{2} \mathrm{NaPO}_{4}$ used in competition experiments were analytical grade. A stock solution of $1000 \mathrm{mg} \mathrm{L}^{-1} \mathrm{Sb}(\mathrm{v})$ was made by dissolving $\mathrm{Sb}_{2} \mathrm{O}_{5}$ in $4.5 \mathrm{M}$ hydrochloric acid. Nitric acid (Romil SpA super purity, 67-69 wt\%) and hydrochloric acid (Merck suprapur, 30\%) were used for sample dilution for ICPMS measurement. In all samples and solutions deionized water (Millipore, $18.2 \mathrm{M} \Omega \mathrm{cm}$ at $25{ }^{\circ} \mathrm{C}$ ) was used. Chemicals used in synthesis are listed as ESI, Section S1. $\dagger$

\subsection{Synthesis}

Granular $\mathrm{ZrO}_{2}$. Granular $\mathrm{ZrO}_{2}$ (GZR) was synthesized by a precipitation method. ${ }^{12}$ In a typical batch, $45.8 \mathrm{~g}$ of $\mathrm{ZrCl}_{4}$ was dissolved into $2 \mathrm{~L}$ of $3 \mathrm{M} \mathrm{HCl}$ under constant stirring. $\mathrm{ZrO}_{2}$ was precipitated by slowly adding concentrated ammonia until $\mathrm{pH}$ reached 7.8. The precipitate was let to settle for $30 \mathrm{~min}$ after which supernatant was discarded. The product was washed several times with deionized water until the interface between the slurry and supernatant remained turbid after settling for $1 \mathrm{~h}$. The separated slurry was dried in an oven at $70{ }^{\circ} \mathrm{C}$ for 4 days. The synthesis resulted in approximately $30 \mathrm{~g}$ of final product that was ground and sieved through a $74 \mu \mathrm{m}(200 \mathrm{mesh})$ sieve for experiments.

Fibrous $\mathrm{ZrO}_{2} \cdot \mathrm{ZrO}_{2}$ fibers (FZR) were produced by electroblowing a solution containing $\mathrm{ZrOCl}_{2}$ and polyvinylpyrrolidone (PVP) followed by calcination. In the synthesis, $34 \mathrm{~g}$ of $\mathrm{ZrOCl}_{2}$ $\cdot 8 \mathrm{H}_{2} \mathrm{O}$ was first dissolved in $91 \mathrm{~mL}$ of water and the obtained solution was mixed with $12 \mathrm{wt} \% \mathrm{PVP} / \mathrm{ethanol}$ solution. The fibers were prepared by electroblowing using a self-made apparatus based on the work by Holopainen and Ritala. ${ }^{36}$ Compressed air was led to a gas-water separator followed by a pressure regulator and finally through a $2.5 \mathrm{~mm}$ metal adapter. An A $27 \mathrm{G}(0.21 \mathrm{~mm} \varnothing)$ needle was placed at the center of the adapter. Additional gas was fed to system from the both 
sides of the apparatus to keep the relative humidity below $15 \%$ at $22 \pm 1{ }^{\circ} \mathrm{C}$. The gas flow rate was adjusted to $40 \mathrm{NL} \mathrm{min}^{-1}$ using a gas flow meter. After the appropriate conditions were achieved the high-voltage power source connected to the metal adapter was switched on to set the potential between the inlet and collector at $15 \mathrm{kV}$ and the $\mathrm{PVP} / \mathrm{Zr}$ solution was pumped through the needle with a syringe pump. The fibers were collected on grounded cylindrical side and vertical back collectors made of steel grid. The prepared fibers were calcined in air at $350{ }^{\circ} \mathrm{C}$ for $6 \mathrm{~h}$ with a heating rate of $5{ }^{\circ} \mathrm{C} \mathrm{min}^{-1}$.

\subsection{Characterization}

Composition analysis. Thermogravimetric and differential scanning calorimetry analysis (TGA-DSC, Netzsch STA 449 F3 Jupiter) was conducted to determine the purity of zirconium oxide materials. Products were heated from 40 to $1000{ }^{\circ} \mathrm{C}$ with a heating rate of $10{ }^{\circ} \mathrm{C} \mathrm{min}^{-1}$ in a helium atmosphere. The vaporized gases were analyzed with an Agilent 7890B/5977A gas chromatograph-mass selective detector (GC-MSD) system.

Morphology and structure analysis. Morphology of the zirconium oxide materials was analyzed using a field emission scanning electron microscope (FESEM, Hitachi S-4800). Samples were coated with a $4 \mathrm{~nm}$ thick Au-Pd alloy before imaging. Crystal structures of the products were analyzed using a powder X-ray diffraction (XRD) technique (PANalytical X'Pert 3 Powder, $\mathrm{Cu} \mathrm{K}_{\alpha 1}$ ). Data was collected in a continuous mode with a step size of $0.01^{\circ}$ using a 10 s counting time per step with a $2 \theta$ range from $5^{\circ}$ to $70^{\circ}$. A specific surface area and porosity of the materials were analyzed using a Brunauer-Emmett-Teller (BET) $\mathrm{N}_{2}$ adsorption measurement (Micrometrics ASAP 2020). Samples were degassed by heating before the analysis after which $\mathrm{N}_{2}$ adsorption measurement was conducted at $-196{ }^{\circ} \mathrm{C}$ by adsorption/desorption method.

Titration. $\mathrm{ZrO}_{2}$ materials were titrated using a batch method in which $20 \mathrm{mg}$ of adsorbent was mixed with $10 \mathrm{~mL}$ of water. Different amounts $(0-175 \mu \mathrm{L})$ of $0.1 \mathrm{M} \mathrm{NaOH}$ were added into the samples and the samples were agitated for $24 \mathrm{~h}$ in a constant rotary mixer $(50 \mathrm{rpm})$ before $\mathrm{pH}$ measurement. The $\mathrm{NaOH}$ additions and the $\mathrm{pH}$ measurements were repeated until the $\mathrm{pH}$ reached a constant value.

Zeta potential. Isoelectric points (IEP) were determined with a Malvern Zetasizer Nano ZC. The experiment was conducted by a batch method in which $20 \mathrm{mg}$ of GZR or FZR was mixed with $10 \mathrm{~mL}$ of $0.01 \mathrm{M} \mathrm{NaNO}_{3}$ or solutions containing 10 or $40 \mathrm{mg} \mathrm{L}^{-1}$ $\mathrm{Sb}(\mathrm{v})$ in addition to $0.01 \mathrm{M} \mathrm{NaNO}_{3}$. The $\mathrm{pH}$ of each sample was set separately into a range of 4 to 10 using a small volume of $\mathrm{HCl}$ or $\mathrm{NaOH}$ solution. The samples were equilibrated for one day followed by equilibrium $\mathrm{pH}$ measurement. The samples were let to settle for a few minutes before determination of equilibrium potential with the Zetasizer.

XANES. Both FZR and GZR were loaded with $30 \mathrm{mg} \mathrm{g}^{-1} \mathrm{Sb}(\mathrm{v})$ at pH 4.0 by mixing $50 \mathrm{mg}$ adsorbent with $50 \mathrm{~mL}$ of $30 \mathrm{mg} \mathrm{L}^{-1} \mathrm{Sb}(\mathrm{v})$ solution. The samples were equilibrated $24 \mathrm{~h}$ before the phase separation. The concentration of $\mathrm{Sb}(\mathrm{v})$ in supernatant was measured to ensure loading degree of the samples and the adsorbents were dried at $35^{\circ} \mathrm{C}$. The dried samples were mixed with cellulose and pressed into pellets. X-ray adsorption near edge structure (XANES) Sb K-edge spectra of Sb loaded GZR and FZR were measured together with $\mathrm{Sb}_{2} \mathrm{O}_{5}$ and $\mathrm{Sb}_{2} \mathrm{O}_{3}$ standard samples at PETRA III P64 beamline, The Deutsches Elektronen-Synchrotron (DESY), Germany. ${ }^{37}$ The spectra was collected in a fluorescence mode at $-196{ }^{\circ} \mathrm{C}$ and a Si311 monochromator was used.

\subsection{Batch adsorption methods}

Effect of pH. The effect of $\mathrm{pH}$ on $\mathrm{Sb}(\mathrm{v})$ sorption on the materials was examined over the $\mathrm{pH}$ range from 1 to 11 . Batch samples were prepared using $2 \mathrm{~g} \mathrm{~L}^{-1}$ adsorbent concentration, and $10 \mathrm{mg} \mathrm{L}^{-1}\left(0.082 \mathrm{mmol} \mathrm{L}^{-1}\right) \mathrm{Sb}(\mathrm{v})$ in $0.01 \mathrm{M} \mathrm{NaNO}_{3}$ solution. The $\mathrm{pH}$ of the solution was adjusted with a small amount of either $\mathrm{NaOH}$ or $\mathrm{HCl}$. The samples were equilibrated for $24 \mathrm{~h}$ before phase separation that was carried out by centrifugation at $2100 \mathrm{~g}$ for $10 \mathrm{~min}$ followed by syringe filtration (Acrodisc LC $0.2 \mu \mathrm{m}$ PVDF). Equilibrium $\mathrm{pH}$ values were determined after the phase separation. Sample aliquots were taken and diluted with an acid mixture of $\mathrm{HCl}$ and $\mathrm{HNO}_{3}$ for $\mathrm{Sb}$ concentration measurement with an Agilent 7800 ICP-MS.

Kinetics. The adsorption kinetics were studied by weighting $200 \mathrm{mg}$ of zirconium oxide materials into beakers and mixing them with $100 \mathrm{~mL}$ of solution containing $10 \mathrm{mg} \mathrm{L}^{-1} \mathrm{Sb}(\mathrm{v})$ in $0.01 \mathrm{M} \mathrm{NaNO}_{3}$ (pH 4.0). A suspension was constantly stirred with a magnetic bar to keep it homogeneous. Samples were taken at specific time intervals, the first sample being immediate and the last one being taken after one week. The samples were phase separated by a short centrifugation (2100g) and syringe filtration $(0.2 \mu \mathrm{m})$ so that the separation would be as fast as possible.

Effect of coexisting ions. The influence of coexisting ions or complexes $\mathrm{NO}_{3}{ }^{-}, \mathrm{H}_{2} \mathrm{CO}_{3}, \mathrm{SO}_{4}{ }^{2-}$ and $\mathrm{H}_{2} \mathrm{PO}_{4}{ }^{-}$on $\mathrm{Sb}(\mathrm{v})$ uptake were studied in four different concentrations $0,1,5$ and $10 \mathrm{mM}$. The same $\mathrm{Sb}(\mathrm{v})$ and adsorbent concentrations $\left(10 \mathrm{mg} \mathrm{L}^{-1}\right.$ and $2.0 \mathrm{~g} \mathrm{~L}^{-1}$, respectively) were used as before and $\mathrm{pH}$ was adjusted to 4.0 with either $\mathrm{HCl}$ or $\mathrm{NaOH}$. Samples were equilibrated $24 \mathrm{~h}$ before the phase separation.

Adsorption isotherms. The effect of temperature to adsorption capacity was investigated by isotherm method in three temperatures 13,22 and $33{ }^{\circ} \mathrm{C}$. In this experiment, adsorbent dose of $0.25 \mathrm{~g} \mathrm{~L}^{-1}$ was used and initial $\mathrm{Sb}(\mathrm{v})$ concentration was ranging from 1 to $30 \mathrm{mg} \mathrm{L}^{-1}$ in $0.01 \mathrm{M} \mathrm{NaNO}_{3}$ at $\mathrm{pH} 4.0$. The solutions were balanced to wanted temperature before mixing with the adsorbents. The mixed samples were equilibrated in these same temperatures $24 \mathrm{~h}$ before the phase separation that was conducted in the same manner as described earlier.

Results of the $\mathrm{pH}$ and kinetic studies were presented as distribution coefficients, $K_{\mathrm{d}}$, as a function of $\mathrm{pH}$ or time. The distribution coefficient describes the distribution of elements between solid and solution phases. $K_{\mathrm{d}}$ was calculated using eqn (1):

$$
K_{\mathrm{d}}=\frac{\left(C_{0}-C_{\mathrm{eq}}\right) V}{C_{\mathrm{eq}} m}
$$

where $K_{\mathrm{d}}\left(\mathrm{mL} \mathrm{g}^{-1}\right)$ is the distribution coefficient, $C_{0}$ and $C_{\text {eq }}$ are the initial and equilibrium concentrations $\left(\mathrm{mg} \mathrm{L}^{-1}\right)$ respectively, $V$ is the sample volume $(\mathrm{mL})$ and $m$ is the mass $(\mathrm{g})$ of dry 
adsorbent. The $\mathrm{Sb}(\mathrm{v})$ adsorption capacities of the materials were calculated with eqn (2):

$$
q_{\mathrm{eq}}=\frac{\left(C_{0}-C_{\mathrm{eq}}\right) V}{m},
$$

where $q_{\text {eq }}\left(\mathrm{mg} \mathrm{g}^{-1}\right)$ is the adsorption capacity, and the other factors are the same as in the previous equation but the volume unit is liters (L).

\subsection{Pressure test}

Pressure buildup in the columns packed with $0.25 \mathrm{~g}$ of GZR or FZR was determined with solution feeding rates of 5, 25, 50 and $75 \mathrm{~mL} \mathrm{~h}^{-1}$ that were controlled with a peristaltic pump. Both GZR and FZR were packed into low-pressure Bio-Rad Econocolumns that were $0.7 \mathrm{~cm}$ in diameter. Columns were connected to a pressure sensor and pressure buildup was measured 30 minutes after starting the peristaltic pump. Pressure was released before moving on the next feeding rate.

\section{Results and discussion}

\subsection{Structural and chemical analysis}

The synthesis $\mathrm{pH}$ of GZR was set to 7.8 that would favor the formation of tetragonal structure of zirconia which is well known to be the active phase considering the materials sorption properties. ${ }^{38}$ The random agglomeration of small crystals resulted in precipitation of a course, hard cake in a slightly pink color (Fig. 1a and b). The obtained $30 \mathrm{~g}$ of hydrous zirconium dioxide $\left(\mathrm{ZrO}_{2} \cdot 1.1 \mathrm{H}_{2} \mathrm{O}\right.$ according to TG analysis, Fig. $\mathrm{S} 1 \dagger$ ) released some $\mathrm{CO}_{2}$ that was most probably absorbed from the air during the synthesis (TGA-MS graph,
Fig. S1 $\dagger$ ). A clear exothermic peak at $450{ }^{\circ} \mathrm{C}$ appears in DSC due to the formation and orientation of tetragonal crystallites and broader peak above $800{ }^{\circ} \mathrm{C}$ indicating phase transformation to monoclinic. ${ }^{39}$

The spun fiber mats retained their physical form after the calcination $\left(350{ }^{\circ} \mathrm{C}\right)$ and formation of zirconium dioxide. The mats showed some elasticity when bended indicating mechanical strength, but the product was relatively easy to grind into a powder. The low magnification SEM image points out that fibers are intact, smooth and uniform with a mean diameter from 300 to $500 \mathrm{~nm}$ (Fig. 1c). The fibers have a cylindrical shape with a high length to diameter ratio, and no beads or fused fibers are visible. However, with high magnification the fiber shows surface roughness that could arise from crystallite structure of the fiber (Fig. 1d). The total mass loss of the calcined fiber in TGA is only $2.7 \%$ from which approximately a half is the loss of readsorbed water between 40 and $200{ }^{\circ} \mathrm{C}$ (TGA from 40 to $200{ }^{\circ} \mathrm{C}$, Fig. S2 $\dagger$ ). Above $400{ }^{\circ} \mathrm{C}$, where PVP starts to decompose, a $1.5 \%$ weight loss was measured that is linked to burning of polymer residues. ${ }^{\mathbf{4 0}}$ Moreover, FZR shows $\mathrm{CO}_{2}$ releases: first at $500{ }^{\circ} \mathrm{C}$ and later at $900{ }^{\circ} \mathrm{C}$ and $1000{ }^{\circ} \mathrm{C}$ (TGA-MS graph, Fig. S2 $\dagger$ ). Since the total mass loss during the analysis is rather small, the product can be regarded as relatively pure. Nevertheless, this minor residue could weaken materials adsorption properties by blocking the material's surface. However, a relatively high porosity and good adsorption capacity in the isotherm experiment was observed indicating that residual polymer did not significantly interfere with adsorption. A strong increase in the DSC was observed above $800{ }^{\circ} \mathrm{C}$ indicating transformation of tetragonal crystallites to monoclinic (Fig. S2 $\dagger$ ).

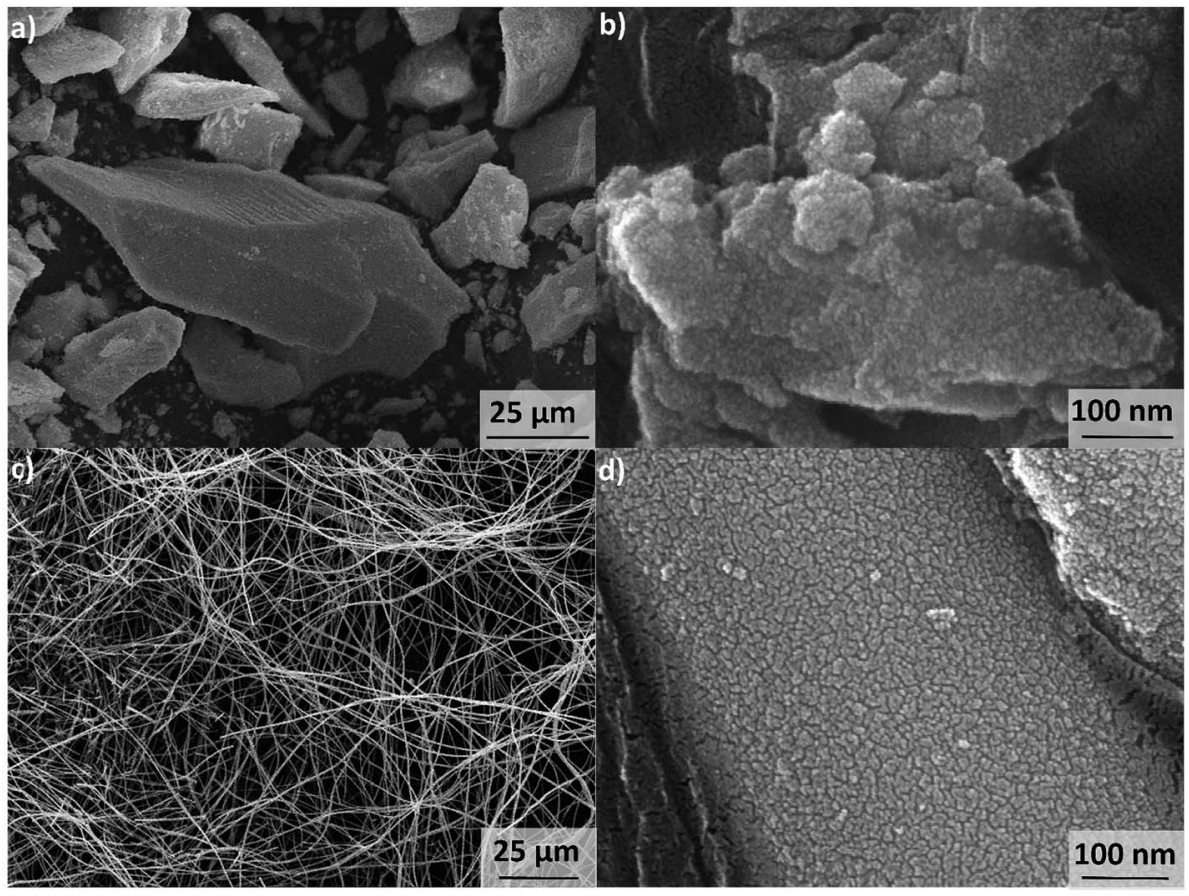

Fig. 1 SEM images of GZR (a) and (b) and FZR (c) and (d). 
XRD. Due to the lack of long-range orientation of crystals in GZR, crystal structure could not be verified by XRD because only a very broad peak at the $2 \theta$ angle of $\sim 30.5^{\circ}$ is observed (Fig. 2). In addition, a Raman spectroscopy analysis of the GZR (and FZR) was unsuccessful because of strong fluorescence induced by the material. However, Deshmane and Adewuyi ${ }^{39}$ suggested that the broad peak in XRD would belong to the extremely small tetragonal phase nuclei. Unlike GZR, FZR is showing a crystalline structure with some broadening in the diffractogram. The difference between materials is expected because GZR was annealed only at $70{ }^{\circ} \mathrm{C}$ whereas FZR was made by calcining at $350{ }^{\circ} \mathrm{C}$. Based on the peak intensities of FZR, tetragonal phase is the dominant structure. However, burning of PVP has probably raised the local temperature of material above the set $350{ }^{\circ} \mathrm{C}$ resulting in monoclinic peaks with lower intensities since $\mathrm{ZrO}_{2}$ is known to transforms from amorphous to tetragonal and finally to monoclinic structure during the calcination process with increasing temperature..$^{15,41,42}$ The broadening of the FZR peaks is probably due to a small crystallite size of $\mathrm{ZrO}_{2}$ crystallites in the material but the peaks are nonetheless sharp compared to the GZR peak. A rough estimation of the crystallite sizes was calculated using Scherrer's equation. By using a shape factor of 0.9 , the approximate crystallite size of GZR would be $0.77 \mathrm{~nm}$ that is significantly smaller than $7.4 \mathrm{~nm}$ crystallite size of FZR.

BET. The specific surface area, total pore volume and pore diameter were determined for GZR and FZR using the BET method, Table 1. Even if it could be assumed that small diameter fibers have a larger specific surface area than relatively big particles, the case is opposite. GZR is an aggregate of small crystals whereas fiber has a rather uniform surface and a larger crystallite size. In addition, the aggregate structure of GZR increases its porosity compared to dense FZR. Despite the significant differences between the materials, their pore diameters are almost the same and classified as mesopores. Because of GZR's larger pore volume and specific surface area it could provide better adsorption capacity. The specific surface area of GZR, $248 \mathrm{~m}^{2} \mathrm{~g}^{-1}$, is in a good agreement with literature values

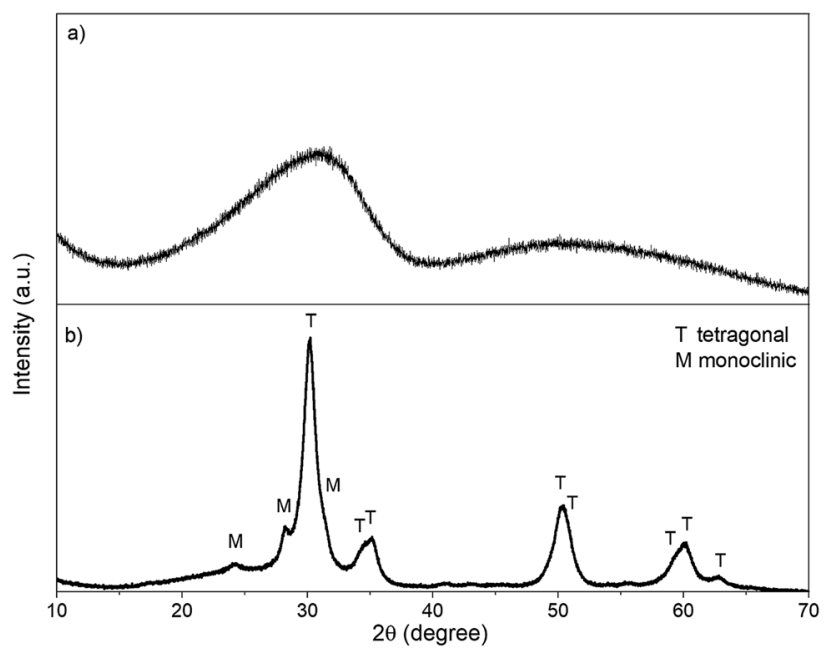

Fig. 2 The XRD pattern of (a) GZR and (b) FZR.
Table 1 Specific surface area, pore volume and pore diameter of GZR and FZR

\begin{tabular}{llll}
\hline & $A_{\mathrm{BET}}{ }^{a}\left(\mathrm{~m}^{2} \mathrm{~g}^{-1}\right)$ & $V_{\text {total }}^{b}\left(\mathrm{~cm}^{3} \mathrm{~g}^{-1}\right)$ & $D_{\text {pore }}^{c}(\mathrm{~nm})$ \\
\hline GZR & 248 & 0.103 & 3.3 \\
FZR & 72 & 0.055 & 3.3
\end{tabular}

${ }^{a} A_{\mathrm{BET}}$ : BET surface area. ${ }^{b} V_{\text {total }}$ : total volume of pores determined by the BET desorption method. ${ }^{c} D_{\text {pore }}$ average pore diameter determined from BET desorption branch.

(53-321 $\mathrm{m}^{2} \mathrm{~g}^{-1}$ ) of products synthesized with a similar method. ${ }^{43-45}$ Correspondingly, the specific surface area of FZR, $72 \mathrm{~m}^{2} \mathrm{~g}^{-1}$, is in the higher end of literature values $\left(5.9-106.3 \mathrm{~m}^{2}\right.$ $\mathrm{g}^{-1}$ ) for pure and doped zirconium oxide nanofibers. ${ }^{14,41,46-48}$

Titration. Potentiometric titration was conducted to determine acidic nature of the zirconium oxide materials, Fig. 3. Acid dissociation constants, $\mathrm{p} K_{\mathrm{a}}$, of GZR and FZR, which are the $\mathrm{pH}$ values at half inflection points, were calculated from the titration data. The $\mathrm{p} K_{\mathrm{a} 1}$ values differ only slightly, being 4.1 for FZR and 4.3 for GZR, which are close to the literature value 4.0 for deprotonation reaction of $\equiv \mathrm{ZrOH}_{2}{ }^{+}$group. ${ }^{49}$ According to these values, FZR is a stronger acid but only with a small difference. In contrast, inflection points of GZR and FZR that are at 505 and $220 \mu \mathrm{mol} \mathrm{g}{ }^{-1}$, respectively, differ considerably. Based on the difference between these points, GZR has significantly more surface hydroxyl groups than FZR that is probably a result of the higher specific surface area of GZR. The high amount of $\mathrm{OH}$ groups and the larger specific surface area together enable a higher adsorption capacity of GZR. When amount of hydroxyl groups are applied together with the specific surface areas, hydroxyl site densities can be calculated for GZR (1.2 sites per $\mathrm{nm}^{2}$ ) and FZR (1.8 sites per $\left.\mathrm{nm}^{2}\right)$.

Zeta potential. The zeta potentials of unloaded GZR and FZR were measured as well as the zeta potentials of GZR and FZR loaded with $5 \mathrm{mg} \mathrm{g}^{-1}$ and $20 \mathrm{mg} \mathrm{g}^{-1}$ of $\mathrm{Sb}(\mathrm{v})$, Fig. 4 . The zeta potential changes as a function of $\mathrm{pH}$ due to protonation and deprotonation reactions of surface $\equiv \mathrm{ZrOH}$ groups as seen below: ${ }^{49,50}$

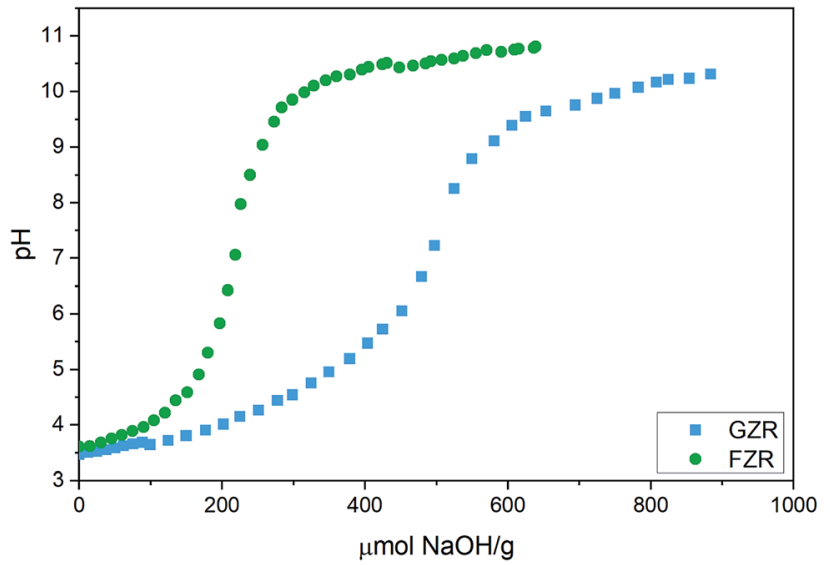

Fig. 3 Potentiometric titration curve of GZR and FZR in deionized water plotted as a function of added $\mathrm{NaOH}$ per gram of dry adsorbent. 

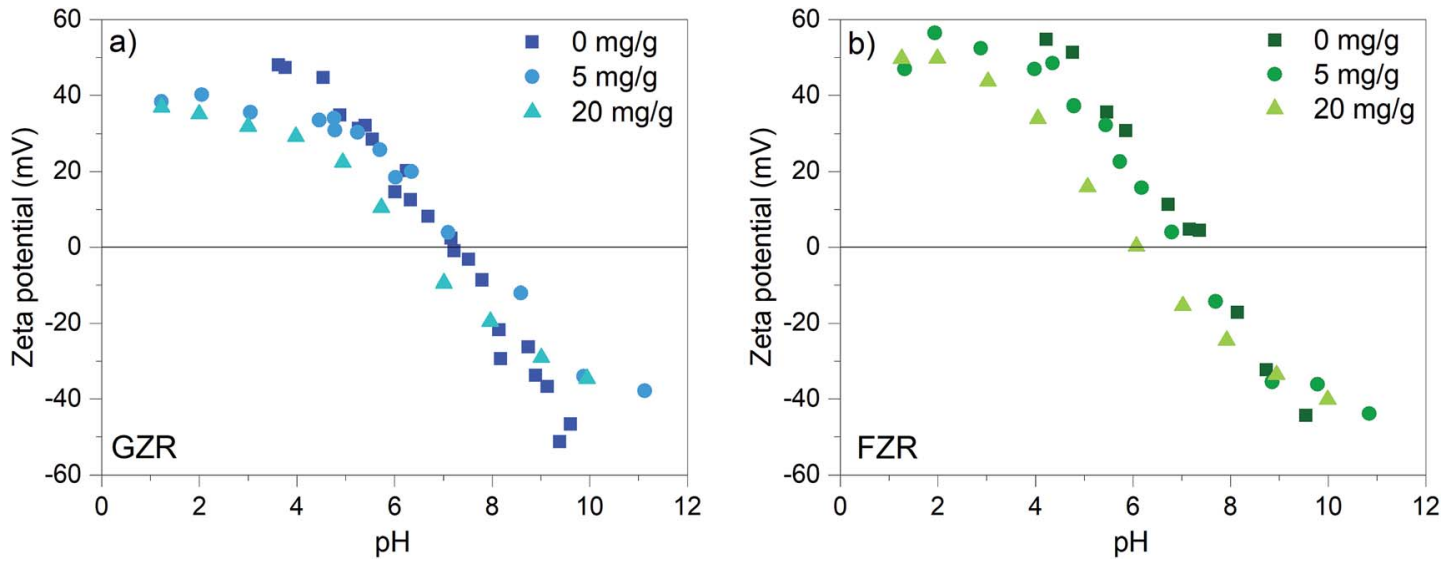

Fig. 4 Zeta potential ( $\mathrm{mV}$ ) of GZR and FZR loaded with 0,5 , and $20 \mathrm{mg} \mathrm{g}^{-1} \mathrm{Sb}(\mathrm{v})$ as a function of $\mathrm{pH}$ in $0.01 \mathrm{M} \mathrm{NaNO}_{3}$, after $24 \mathrm{~h}$ equilibration time.

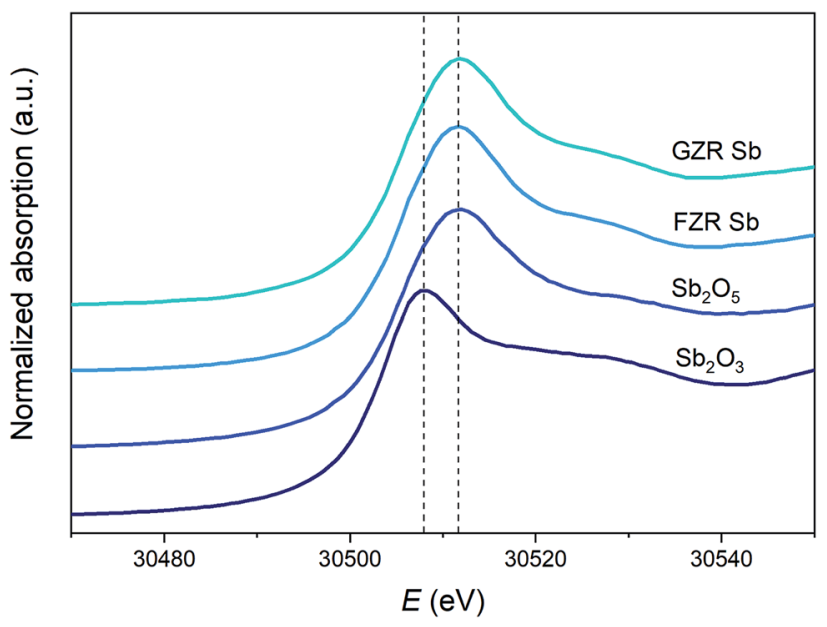

Fig. 5 Normalized XANES Sb K-edge spectra of $\mathrm{Sb}_{2} \mathrm{O}_{5}$ and $\mathrm{Sb}_{2} \mathrm{O}_{3}$ references, and $30 \mathrm{mg} \mathrm{g}^{-1} \mathrm{Sb}$ loaded GZR and FZR samples.

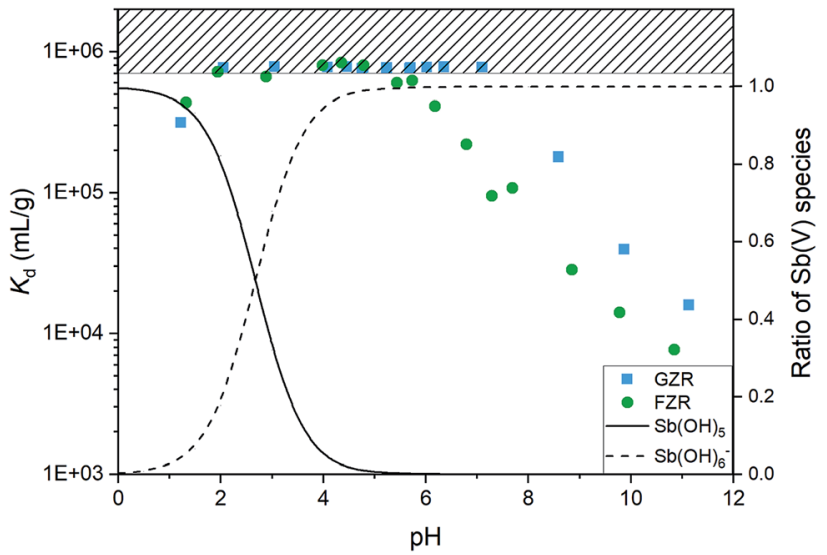

Fig. 6 The distribution coefficient $\left(K_{d}\right)$ of $\mathrm{Sb}(\mathrm{V})$ after 1 day equilibrium time for GZR and FZR as a function of $\mathrm{pH}$ in $0.01 \mathrm{M} \mathrm{NaNO}_{3}$ and the relative abundance of $\mathrm{Sb}(\mathrm{OH})_{5}$ and $\mathrm{Sb}(\mathrm{OH})_{6}{ }^{-}$species obtained from PHREEQC modelling utilizing sit-database of the program.

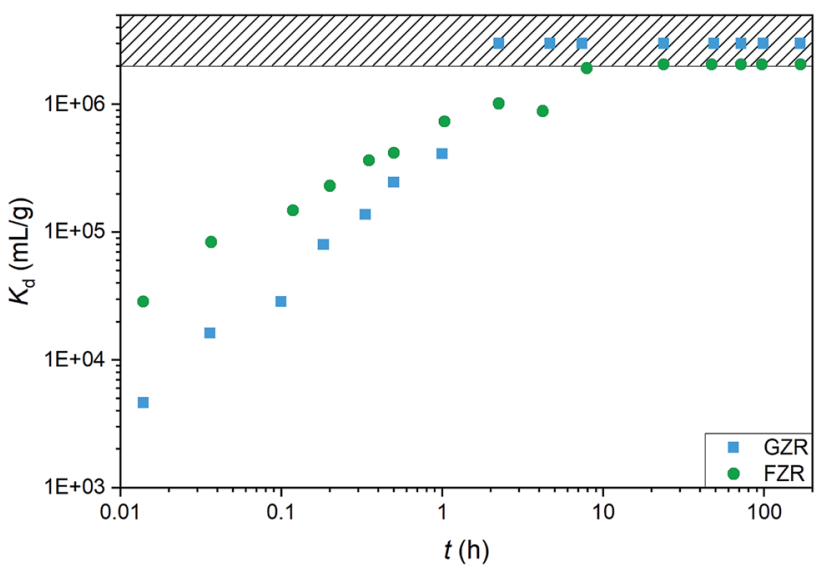

Fig. 7 The $\mathrm{Sb}(\mathrm{V})$ adsorption kinetics on GZR and FZR presented as $K_{\mathrm{d}}$ $\left(\mathrm{mL} \mathrm{g}^{-1}\right)$ as a function of time (h) in $10 \mathrm{ppm} \mathrm{Sb}(\mathrm{v})$ and $0.01 \mathrm{M} \mathrm{NaNO}_{3}$ at $\mathrm{pH} 4.0 \pm 0.2$.

$$
\begin{gathered}
\equiv \mathrm{ZrOH}_{2}^{+} \leftrightharpoons \equiv \mathrm{ZrOH}+\mathrm{H}^{+} \\
\equiv \mathrm{ZrOH} \leftrightharpoons \equiv \mathrm{ZrO}^{-}+\mathrm{H}^{+}
\end{gathered}
$$

At low $\mathrm{pH}$, the surface groups are positive $\equiv \mathrm{ZrOH}_{2}{ }^{+}$and in alkaline conditions the surface charge is negative because of $\equiv \mathrm{ZrO}^{-}$groups. At the isoelectric points (IEP), the surface group charges are in balance and the net charge of the material is zero. The isoelectric point of FZR and GZR in $0.01 \mathrm{M} \mathrm{NaNO}_{3}$ are at $\mathrm{pH}$ 7.4 and 7.2, respectively, which are in the typical range from 4 to 11 observed for $\mathrm{ZrO}_{2} \cdot{ }^{51}$ By loading the materials with $5 \mathrm{mg} \mathrm{g}^{-1}$ of $\mathrm{Sb}(\mathrm{v})$, the IEP of FZR decreases slightly compared to unloaded material but no difference can be observed in the case of GZR. When materials were loaded with $20 \mathrm{mg} \mathrm{g}^{-1}$ of $\mathrm{Sb}(\mathrm{v})$, the IEP shift is more obvious and visible for both materials. The IEP of FZR with $20 \mathrm{mg} \mathrm{g}^{-1} \mathrm{Sb}(\mathrm{v})$ loading is 6.0 and that of GZR is 6.2. The observed decrease of the IEP value during adsorption is proposed to be due to an inner-sphere complexation of $\mathrm{Sb}(\mathrm{OH})_{6}{ }^{-26,52,53}$ Essington and Stewart ${ }^{54}$ suggested that $\mathrm{Sb}(\mathrm{v})$ 

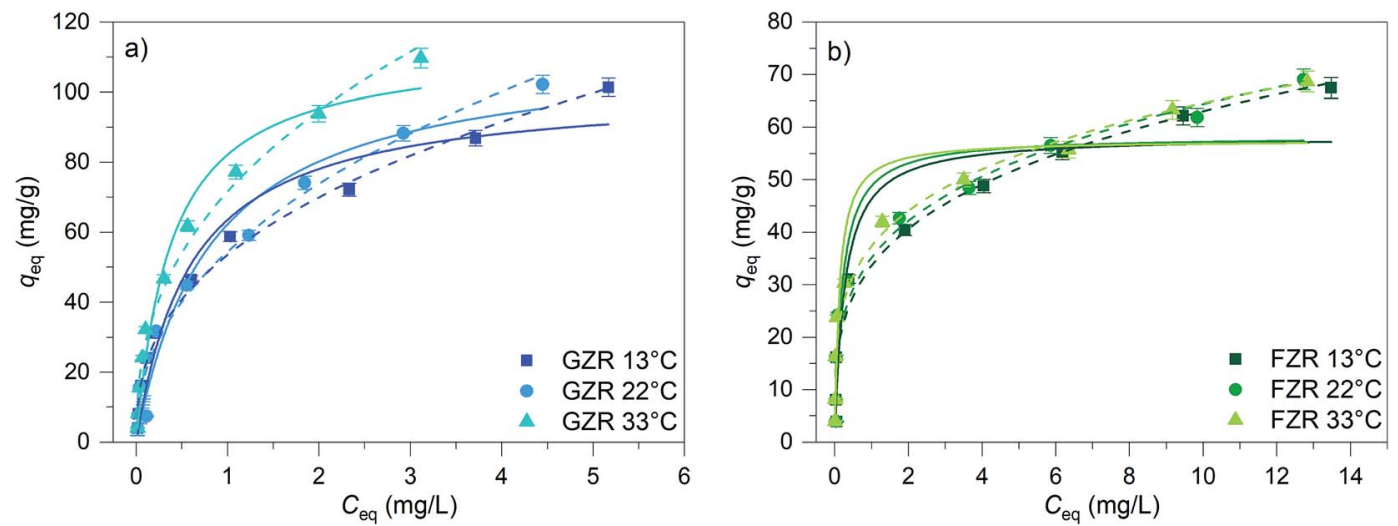

Fig. 8 The $\mathrm{Sb}(\mathrm{v})$ isotherms of GZR and FZR at $\mathrm{pH} 4.0 \pm 0.1$ after 24 h equilibrium time at 13,22 and $33^{\circ} \mathrm{C}$. The initial concentration of $\mathrm{Sb}(\mathrm{v})$ was $1-$ $30 \mathrm{mg} \mathrm{L}^{-1}$ in $0.01 \mathrm{M} \mathrm{NaNO}_{3}$ and adsorbent concentration was $0.25 \mathrm{~g} \mathrm{~L}^{-1}$. Solid lines present Langmuir and dashed lines Freundlich fittings.

adsorption on gibbsite, $\mathrm{Al}(\mathrm{OH})_{3}$, would happen through both inner- and outer-sphere complexation reactions (5) and (6), respectively, presented below for zirconia:

$$
\begin{gathered}
\equiv \mathrm{ZrOH}+\mathrm{Sb}(\mathrm{OH})_{6}{ }^{-} \leftrightharpoons \equiv \mathrm{ZrOSb}(\mathrm{OH})_{5}{ }^{-}+\mathrm{H}_{2} \mathrm{O} \\
\equiv \mathrm{ZrOH}+\mathrm{H}^{+}+\mathrm{Sb}(\mathrm{OH})_{6}{ }^{-} \leftrightharpoons \equiv \mathrm{ZrOH}_{2}{ }^{+}-\mathrm{Sb}(\mathrm{OH})_{6}{ }^{-}
\end{gathered}
$$

where the charge of surface groups changes in the chemical inner-sphere complexation reaction whereas the charge in the physical outer-sphere complexation remains unchanged.

XANES. To discover the oxidation state of $\mathrm{Sb}$ after adsorption, XANES Sb K-edge spectra of $\mathrm{Sb}_{2} \mathrm{O}_{5}$ and $\mathrm{Sb}_{2} \mathrm{O}_{3}$ standards and $30 \mathrm{mg} \mathrm{g}^{-1} \mathrm{Sb}$ loaded GZR and FZR samples were measured, Fig. 5. In the measured spectra, the absorption edge of $\mathrm{Sb}_{2} \mathrm{O}_{3}$ is evidently lower than that of $\mathrm{Sb}_{2} \mathrm{O}_{5}$. The absorption spectra of $\mathrm{Sb}$ (v) loaded samples seem similar to $\mathrm{Sb}_{2} \mathrm{O}_{5}$ standard indicating that the oxidation state of $\mathrm{Sb}(\mathrm{v})$ remains unchanged during adsorption on these materials. Therefore, a thought about reduction of $\mathrm{Sb}(\mathrm{v})$ to $\mathrm{Sb}(\mathrm{III})$ that has been reported for example in the case of zero-valent iron can be excluded..$^{55,56}$

\section{$3.2 \mathrm{Sb}(\mathrm{v})$ uptake}

The effect of $\mathbf{p H}$. The uptake properties of adsorbents can strongly depend on $\mathrm{pH}$ conditions. For that reason the effect of $\mathrm{pH}$ on $\mathrm{Sb}(\mathrm{v})$ adsorption properties of both materials was investigated. The optimal $\mathrm{pH}$ for the $\mathrm{Sb}(\mathrm{v})$ uptake is from 2 to 6 and from 2 to 7 for FZR and GZR, respectively, Fig. 6. At this pH range they perform at an excellent level of $\mathrm{Sb}(\mathrm{v})$ uptake by reaching $K_{\mathrm{d}}$ over $600000 \mathrm{~mL} \mathrm{~g}^{-1}$. In fact, the equilibrium $\mathrm{Sb}(\mathrm{v})$ concentration was below the ICP-MS detection limit of $0.07 \mu \mathrm{g}$ $\mathrm{L}^{-1}$ with almost all the samples in this $\mathrm{pH}$ range. At this optimal $\mathrm{pH}$ range, adsorption is facilitated by electrostatic attraction between positively charged adsorbent surface and negatively charged $\mathrm{Sb}(\mathrm{OH})_{6}{ }^{-}$. Below pH $2, K_{\mathrm{d}}$ value decreases towards more acidic conditions, that can be attributed to electrically neutral $\mathrm{Sb}(\mathrm{OH})_{5}$ species that becomes prevalent instead of $\mathrm{Sb}(\mathrm{OH})_{6}{ }^{-}$. A decrease of the $K_{\mathrm{d}}$ as a function $\mathrm{pH}$ in the alkaline end can be explained by gradually emerging negative surface charge of the materials that repulses the prevailing $\mathrm{Sb}(\mathrm{OH})_{6}{ }^{-}$species, Fig. 4 and 6 . However, the rising $\mathrm{pH}$ do not totally prevent adsorption but probably increases an energy barrier between $\mathrm{Sb}(\mathrm{OH})_{6}{ }^{-}$and the negatively charged surface slowing down the adsorption reaction.

The decrease of the $K_{\mathrm{d}}$ value in GZR system starts at the IEP when the net charge of the surface becomes negative. Even though the $K_{\mathrm{d}}$ value decreases from $\mathrm{pH}_{\mathrm{IEP}}$ onwards, GZR performs on good level since it is able to uptake still $99.8 \%\left(K_{\mathrm{d}} 180000 \mathrm{~mL} \mathrm{~g}^{-1}\right)$ of $\mathrm{Sb}(\mathrm{v})$ at $\mathrm{pH} 8$ and even in the most alkaline sample $97.0 \%\left(K_{\mathrm{d}}\right.$ $16000 \mathrm{~mL} \mathrm{~g}^{-1}$ ). Different from GZR, the $\mathrm{Sb}(\mathrm{v})$ uptake of FZR decreases already below material's $\mathrm{pH}_{\mathrm{IEP}}$. The decrease could be attributed to larger surface coverage on FZR surface causing greater

\begin{tabular}{|c|c|c|c|c|c|c|c|}
\hline & $T\left({ }^{\circ} \mathrm{C}\right)$ & \multicolumn{3}{|l|}{ Langmuir } & \multicolumn{3}{|l|}{ Freundlich } \\
\hline & 22 & 113 & 1.2 & 0.947 & 54 & 2.3 & 0.971 \\
\hline & 33 & 113 & 2.6 & 0.969 & 72 & 2.5 & 0.982 \\
\hline FZR & 13 & 58 & 3.9 & 0.885 & 34 & 3.7 & 0.950 \\
\hline
\end{tabular}

Table 2 Langmuir and Freundlich adsorption parameters for GZR and FZR obtained from $\mathrm{Sb}(\mathrm{v})$ isotherms at 13,22 and $33^{\circ} \mathrm{C}$ 
repulsion between adsorbed and solute $\mathrm{Sb}(\mathrm{OH})_{6}{ }^{-}$. Despite the possible repulsion, FZR is able to uptake even $99.5 \%\left(K_{\mathrm{d}} 108000 \mathrm{~mL}\right.$ $\left.\mathrm{g}^{-1}\right)$ at $\mathrm{pH} 8$ and $93.8 \%\left(K_{\mathrm{d}} 7700 \mathrm{~mL} \mathrm{~g}^{-1}\right)$ at $\mathrm{pH} 11$.

Kinetics. An adsorption kinetic study was conducted to determine adsorption rates of $\mathrm{Sb}(\mathrm{v})$ on GZR and FZR surfaces, Fig. 7. The adsorption kinetics is very fast for both materials, FZR being slightly faster in the beginning of the experiment. FZR achieves $99 \%\left(K_{\mathrm{d}}>2000000 \mathrm{~mL} \mathrm{~g}^{-1}\right)$ adsorption in $2 \mathrm{~min}$ and GZR in $11 \mathrm{~min}$, and they reach the detection limit, $0.025 \mu \mathrm{g}$ $\mathrm{L}^{-1}$, after 7 and 2 hours, respectively. On this basis, both materials are suitable for a continuous purification process where fast kinetics is essential for an effective separation. At low $\mathrm{Sb}$ concentrations where high capacity is unnecessary, FZR probably performs better than GZR, but when a higher adsorption capacity is required, GZR should provide more efficient removal.

The kinetic data was analyzed according to the pseudo-first and pseudo-second-order rate laws in their nonlinear forms. ${ }^{57}$ The pseudo-first-order equation can be presented as

$$
q_{t}=q_{\mathrm{eq}}\left[1-\exp \left(-k_{1} t\right)\right]
$$

where $t(\mathrm{~min})$ is time, $k_{1}\left(\mathrm{~min}^{-1}\right)$ is the pseudo-first-order rate constant, $q_{t}\left(\mathrm{mg} \mathrm{g}^{-1}\right)$ is amount of adsorbed $\mathrm{Sb}(\mathrm{v})$ at a given time and $q_{\mathrm{eq}}\left(\mathrm{mg} \mathrm{\textrm {g } ^ { - 1 } )}\right.$ is an equilibrium capacity. Adsorption following the pseudo-first-order model kinetics is supposed to be limited by an intraparticle diffusion. ${ }^{58}$ Whereas, in the pseudo-second-order kinetics, surface adsorption is assumed to be the rate limiting step, where adsorption is due to a chemical interaction between the adsorbate $\left(\mathrm{Sb}(\mathrm{OH})_{6}{ }^{-}\right)$in a solution phase and the adsorbent surface. ${ }^{\mathbf{5 8 , 5 9}}$ The pseudo-second-order rate kinetics can be expressed as

$$
q_{t}=q_{\mathrm{eq}} \frac{k_{2}^{*} t}{1+k_{2}^{*} t}, \text { where } k_{2}^{*}=k_{2} q_{\mathrm{eq}}
$$

with $k_{2}\left(\mathrm{~g} \mathrm{mg}^{-1} \mathrm{~min}^{-1}\right)$ pseudo-second-order rate constant. When the results are presented as $q_{t}$ as a function of $t$, eqn (7) and (8) can be fitted to the graph from which the rate constants can be calculated. Fittings are given as ESI, Fig. S3.† The kinetic parameters calculated from the data before reaching the detection limit are presented in Table S1 as ESI. $\uparrow$ The high coefficient of determination $\left(R^{2}\right)$ of the pseudo-second-order rate model ( $R^{2}$ is 0.988 for GZR and 0.992 for FZR) indicates it to be more probable than the pseudo-first-order reaction $\left(R^{2}\right.$ is 0.920 for GZR and 0.887 for FZR). This indicates chemisorption to possibly be the rate limiting step in the $\mathrm{Sb}(\mathrm{v})$ adsorption process where sorption takes place by exchanging or sharing electrons between the sorbent and adsorbate. ${ }^{58,60}$

Adsorption capacity. The $\mathrm{Sb}(\mathrm{v})$ adsorption capacity was determined by an isotherm method for GZR and FZR at $\mathrm{pH} 4.0$ \pm 0.1 in the $1-30 \mathrm{mg} \mathrm{L}^{-1} \mathrm{Sb}(\mathrm{v})$ solution, Fig. 8. A slight increase in $\mathrm{pH}$ was observed during the experiment indicating release of $\mathrm{OH}^{-}$ions into solution that could be caused by inner-sphere complexation or ligand exchange reaction. At low equilibrium concentration, the adsorption capacity increases strongly when the concentration increases and at higher concentrations the adsorption capacity approaches the maximum capacity asymptotically. Moreover, temperature affects $\mathrm{Sb}(\mathrm{v})$ adsorption on GZR by increasing adsorption capacity with the increase of temperature, indicating an endothermic adsorption process or enhanced intraparticle diffusion. In contrast to GZR, $\mathrm{Sb}(\mathrm{v})$ adsorption on FZR is practically unaffected by the temperature. The difference between the capacities of GZR $\left(113 \mathrm{mg} \mathrm{g}^{-1}\right)$ and FZR (58 $\mathrm{mg} \mathrm{g}^{-1}$ ) at $22{ }^{\circ} \mathrm{C}$ could originate from the higher calcination temperature of FZR. High calcination temperatures are known to increase crystallite size and thereby decreasing the specific surface area and porosity leading to the lower adsorption capacities. Both Langmuir and Freundlich equations, numbered as (9) and (10), respectively, were fitted to the data series to obtain adsorption parameters: ${ }^{61}$

$$
\begin{aligned}
& q_{\mathrm{eq}}=\frac{q_{\mathrm{m}} k_{\mathrm{L}} C_{\mathrm{eq}}}{1+k_{\mathrm{L}} C_{\mathrm{eq}}} \\
& q_{\mathrm{eq}}=k_{\mathrm{F}} C_{\mathrm{eq}}^{1 / n},
\end{aligned}
$$

where $q_{\text {eq }}\left(\mathrm{mg} \mathrm{g}^{-1}\right)$ is the adsorption capacity and $C_{\text {eq }}\left(\mathrm{mg} \mathrm{L}^{-1}\right)$ is the equilibrium concentration of $\mathrm{Sb}(\mathrm{v})$ in both equations. The Langmuir parameter $q_{\mathrm{m}}\left(\mathrm{mg} \mathrm{g}^{-1}\right)$ is the maximum $\mathrm{Sb}(\mathrm{v})$ adsorption capacity and $k_{\mathrm{L}}\left(\mathrm{mg} \mathrm{L}^{-1}\right)$ is an adsorption equilibrium constant. The $k_{\mathrm{F}}\left(\mathrm{g} \mathrm{mg}^{-1} \mathrm{~L}^{-1}\right)$ is the Freundlich adsorption constant and $n$ is an exponential parameter. For the favorable adsorption reaction, the $n$ parameter is usually between 1 and 10. The analyzed parameters for adsorption are given in Table 2 together with the coefficient of determination $\left(R^{2}\right)$.

A high correlation with the Langmuir model is an indication of constant adsorption site energy and asymptotic approach of the full monolayer surface coverage at high concentrations whereas the empirical multilayer Freundlich model assumes that the adsorbent has different adsorption sites. ${ }^{62}$ The $R^{2}$ values of model fittings show that Freundlich model describes $\mathrm{Sb}(\mathrm{v})$ adsorption better than Langmuir model suggesting heterogeneous adsorption. However, as Freundlich model cannot be used to obtain the theoretical maximum adsorption capacity, the theoretical capacities were based on the Langmuir parameter $q_{\mathrm{m}}$ that is $113 \mathrm{mg} \mathrm{g}^{-1}\left(0.928 \mathrm{mmol} \mathrm{g}^{-1}\right)$ for GZR and $58 \mathrm{mg} \mathrm{g}^{-1}\left(0.476 \mathrm{mmol} \mathrm{g}^{-1}\right)$ for FZR at $22{ }^{\circ} \mathrm{C}$. Because of the rather low correlation with the Langmuir model, an experimental adsorption capacity of FZR, $69 \mathrm{mg} \mathrm{g}^{-1}$, exceeds the result of Langmuir model fitting slightly. The capacity of FZR is in a good agreement with earlier $\mathrm{Sb}(\mathrm{v})$ adsorption studies on zirconium based materials such as zirconium oxide ${ }^{26}$ at $\mathrm{pH} 7.0$, $55 \mathrm{mg} \mathrm{g}^{-1}$, zirconium oxide decorated carbon nanofibers ${ }^{\mathbf{1 4}}$ at $\mathrm{pH} 7.0,57 \mathrm{mg} \mathrm{g}^{-1}$, and iron-zirconium bimetal oxide $\mathrm{e}^{26}$ at $\mathrm{pH} 7.0$, $51 \mathrm{mg} \mathrm{g}^{-1}$. However, GZR shows even greater capacity towards $\mathrm{Sb}(\mathrm{v})$ being approximately twice that reported in literature for zirconium oxide.

From the results of the adsorption capacity experiment and the BET surface area measurement, a surface site density can be calculated. The surface site density of GZR is 2.3 sites per $\mathrm{nm}^{2}$ and that of FZR is 4.0 sites per $\mathrm{nm}^{2}$. The site density of FZR is higher but the larger specific surface area of GZR dominates the capacity difference observed in the adsorption isotherms. When the surface site densities are compared 
with the hydroxyl site densities presented before ( 1.2 sites per $\mathrm{nm}^{2}$ for GZR and 1.8 sites per $\mathrm{nm}^{2}$ for FZR) a significant difference can be observed. On this basis, adsorption cannot be explained only with reactions between $\mathrm{Sb}(\mathrm{v})$ and hydroxyl groups. It is likely that there are other kinds of reactive surface groups or mechanisms taking part in the adsorption process such as nucleation, reaction with non-hydrolyzed zirconium or oxygen vacancies.

Effect of coexisting ions. The coexisting ions and complexes can greatly affect $\mathrm{Sb}(\mathrm{v})$ adsorption properties of materials through a competitive adsorption. Therefore, the influence of $\mathrm{NO}_{3}{ }^{-}, \mathrm{H}_{2} \mathrm{CO}_{3}, \mathrm{SO}_{4}{ }^{2-}$ and $\mathrm{H}_{2} \mathrm{PO}_{4}{ }^{-}$on $\mathrm{Sb}(\mathrm{v})$ adsorption onto GZR and FZR were investigated, Fig. 9. Neither $\mathrm{NO}_{3}{ }^{-}$or $\mathrm{H}_{2} \mathrm{CO}_{3}$ notably decreased $\mathrm{Sb}(\mathrm{v})$ adsorption on either of the materials despite several times higher concentrations of $\mathrm{NO}_{3}{ }^{-}$and $\mathrm{H}_{2} \mathrm{CO}_{3}$ compared to $\mathrm{Sb}(\mathrm{v})$. Furthermore, $\mathrm{HCl}$ that was used in $\mathrm{pH}$ adjustment of the samples did not interfere with $\mathrm{Sb}(\mathrm{v})$ adsorption. The low interference caused by $\mathrm{NO}_{3}{ }^{-}$and $\mathrm{Cl}^{-}$on $\mathrm{Sb}(\mathrm{v})$ uptake is often observed ${ }^{26,34,35}$ since $\mathrm{NO}_{3}{ }^{-}$and $\mathrm{Cl}^{-}$ions are mainly retained by electrostatic attraction whereas $\mathrm{Sb}(\mathrm{v})$ is believed to form inner-sphere complexes with the $\mathrm{ZrO}_{2}$ surface. Moreover, the influence of $\mathrm{SO}_{4}{ }^{2-}$ on $\mathrm{Sb}(\mathrm{v})$ uptake was minor since the uptake was decreased from $100 \%$ to $99.5 \%$ in the case of FZR and for GZR the decrease was even smaller. The most significant competition was observed between $\mathrm{H}_{2} \mathrm{PO}_{4}{ }^{-}$and $\mathrm{Sb}(\mathrm{OH})_{6}{ }^{-}$since both antimony and phosphorus belong to the same elemental group 15 having resembling chemical properties. Su et al. ${ }^{21}$ observed that phosphate formed inner-sphere complexes on $\mathrm{Ce}_{0.2} \mathrm{Zr}_{0.8} \mathrm{O}_{2}$ surface and surface $-\mathrm{OH}$ groups had a major influence on phosphate removal. As our findings suggest the same adsorption behavior for $\mathrm{Sb}(\mathrm{v})$ on GZR and FZR, $\mathrm{Sb}(\mathrm{OH})_{6}{ }^{-}$and $\mathrm{H}_{2} \mathrm{PO}_{4}{ }^{-}$are most probably competing from the same adsorption sites resulting in lower uptake percentages of $\mathrm{Sb}(\mathrm{v})$. The observed decrease in the $\mathrm{Sb}(\mathrm{v})$ uptake was larger for FZR than GZR that could arise from differences in the amount of $\mathrm{OH}$ groups that is greater for GZR calcined in the lower temperature.

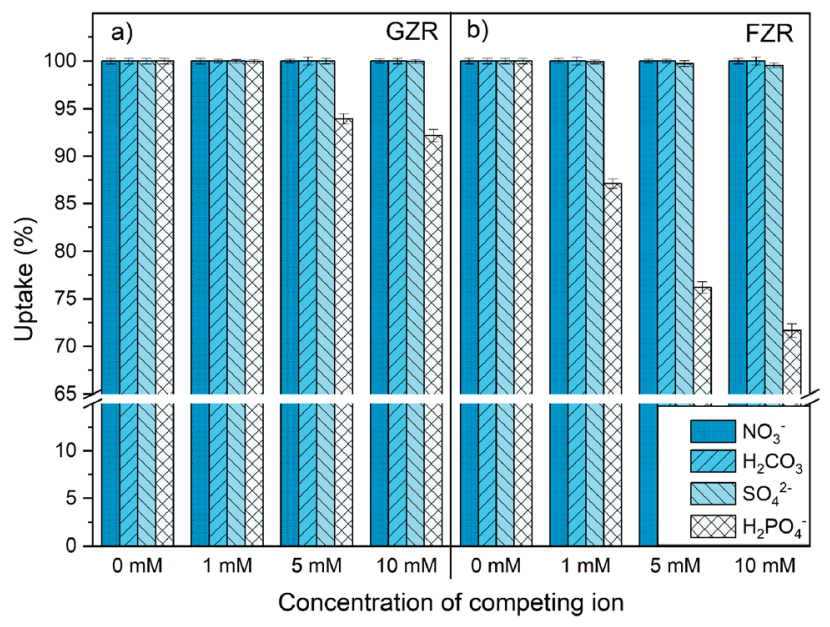

Fig. 9 Effect of $0-10 \mathrm{mM} \mathrm{NO}_{3}{ }^{-}, \mathrm{H}_{2} \mathrm{CO}_{3}, \mathrm{SO}_{4}{ }^{2-}$ and $\mathrm{H}_{2} \mathrm{PO}_{4}{ }^{-}$(prevalent species) on $10 \mathrm{mg} \mathrm{L}^{-1} \mathrm{Sb}(\mathrm{v})$ adsorption onto (a) GZR and (b) FZR at $\mathrm{pH}$ 4.0.

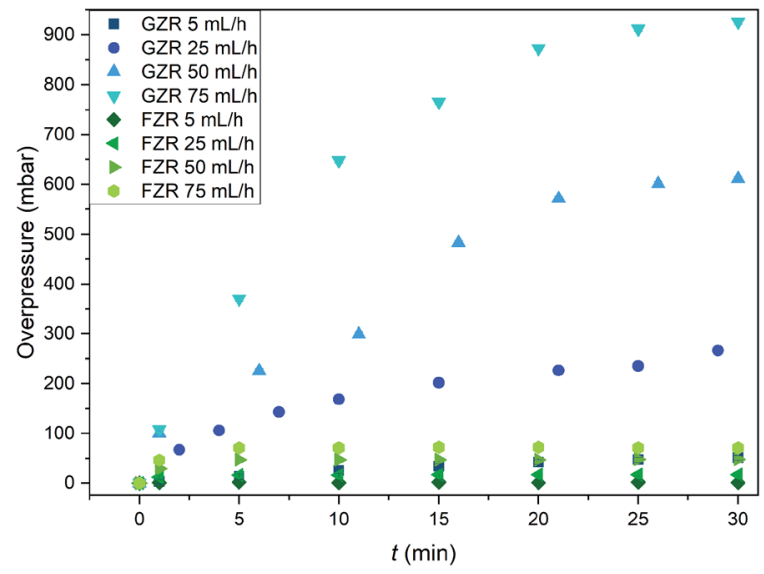

Fig. 10 The overpressure (mbar) generated in the columns packed with $0.25 \mathrm{~g}$ of GZR or FZR at solution feed rates of 5, 25, 50 and $75 \mathrm{~mL}$ $\mathrm{h}^{-1}$ during $30 \mathrm{~min}$ period.

\subsection{Pressure test}

The pressure buildup in the GZR and FZR columns were measured to determine their functioning in packed bed columns since evolution of high pressures can cause severe problems in the purification process, Fig. 10. At the feeding rate of $5 \mathrm{~mL} \mathrm{~h}^{-1}$, which can be considered as a normal feeding rate for packed bed column of this size, the overpressure is low (50 mbar) for GZR and even lower for FZR. However, at higher feeding rates the column packed with GZR is generating significantly more backpressure than FZR. At the highest feeding rate, the overpressure in the GZR column is $930 \mathrm{mbar}$ whereas the overpressure in the FZR column is only $70 \mathrm{mbar}$ that is only small fraction compared to GZR. The difference originates from the physical form of the materials. Small $<74$ $\mu \mathrm{m}$ GZR particles are packing tightly in the column creating notably higher flow resistance than loosely packed selfsupported FZR fibers that are forming 3D webs. Due to the lower flow resistance, formatting zirconia into the fiber could improve the column functioning by retaining low pressures even at higher flow rates. Furthermore, no breaking or fragmentation of the fibers was observed during the experiment that indicates material to be suitable for column separation even with high flow rates.

\section{Conclusions}

In this study, two zirconium oxide materials grains and fibers were synthesized by precipitation and electroblowing methods, respectively, and products compared with each other. The precipitated zirconium oxide formed uneven aggregate grains with broad variation in size and shape that showed amorphous or nanocrystalline structure in XRD. In addition, elastic fibers with cylindrical shape and dominating tetragonal structure were obtained from electroblowing synthesis with an average diameter of 300-500 $\mathrm{nm}$. Both synthesized zirconium oxide materials showed efficient $\mathrm{Sb}(\mathrm{v})$ removal in a wide $\mathrm{pH}$ range enabling their use in various conditions. Furthermore, good 
adsorption capacities were observed in the isotherm experiment in which adsorption capacity of GZR was higher than that of FZR. The good adsorption capacities are probably due to the large specific surface areas and porosities of the materials that were higher for GZR. Both materials had fast kinetics FZR being faster in the beginning of the reaction whereas GZR reached the detection limit earlier because of GZR's higher adsorption capacity. The materials followed pseudo-second-order rate model indicating chemical interaction between surface and $\mathrm{Sb}(\mathrm{v})$ ions that is supported by the IEP shift, negligible competition between $\mathrm{NO}_{3}{ }^{-}$and $\mathrm{Sb}(\mathrm{v})$ and the efficient $\mathrm{Sb}(\mathrm{v})$ uptake also in alkaline conditions where surface charge of the products are negative. This indicates that even though the product morphologies are greatly different from each other the suggested adsorption mechanism stays the same.

Hence, well-working zirconium oxide aggregate can be formatted into submicron fibers but the adsorption capacity is slightly weakened because of higher calcination temperature of fibers that decreases the specific surface area and porosity. The major benefit of FZR was its better mechanical stability, lower pressure buildup in the column and faster adsorption kinetics that could benefit antimony removal in dynamic column operation. Nonetheless, when considering application of these materials in industrial scale, further study is needed to determine optimal conditions for such process by column experiments. In addition, regeneration of the materials would extend materials usability and therefore should be investigated in the future. Overall, these two materials have a great potential to uptake $\mathrm{Sb}(\mathrm{v})$ from different water solutions.

\section{Conflicts of interest}

There are no conflicts to declare.

\section{Acknowledgements}

A XANES experiment of this study was carried out at PETRA III P64 at DESY, a member of the Helmholtz Association (HGF). We thank W. Caliebe for assistance in measurements at P64 beamline. This work was supported by University of Helsinki (Doctoral School in Chemistry and Molecular Sciences). The authors also acknowledge the support of Fortum Power and Heat Oy.

\section{References}

1 Y. Shao, Z. Xu, H. Wan, H. Chen, F. Liu, L. Li and S. Zheng, J. Hazard. Mater., 2010, 179, 135-140.

2 A. V. Borhade, D. R. Tope and J. A. Agashe, J. Mater. Sci.: Mater. Electron., 2018, 29, 7551-7561.

3 R. Zhang, R. He, W. Zhou, Y. Wang and D. Fang, Mater. Des., 2014, 62, 1-6.

4 A. Malolepszy, M. Mazurkiewicz, L. Stobinski, B. Lesiak, L. Kover, J. Toth, B. Mierzwa, A. Borodzinski, F. Nitze and T. Wagberg, Int. J. Hydrogen Energy, 2015, 40, 16724-16733.

5 E. Djurado, P. Bouvier and G. Lucazeau, J. Solid State Chem., 2000, 149, 399-407.
6 M. Kogler, E. Koeck, S. Vanicek, D. Schmidmair, T. Goetsch, M. Stoeger-Pollach, C. Hejny, B. Kloetzer and S. Penner, Inorg. Chem., 2014, 53, 13247-13257.

7 D. G. Lamas, A. M. Rosso, M. S. Anzorena, A. Fernandez, M. G. Bellino, M. D. Cabezas, N. E. Walsoe de Reca and A. F. Craievichc, Scr. Mater., 2006, 55, 553-556.

8 M. Li, Z. Feng, G. Xiong, P. Ying, Q. Xin and C. Li, J. Phys. Chem. B, 2001, 105, 8107-8111.

9 R. Garvie, J. Phys. Chem., 1965, 69, 1238-1243.

10 K. Tsukuma and M. Shimada, J. Mater. Sci., 1985, 20, 11781184.

11 H. Tel, Y. Altas, F. Gur and A. Ugur, Radiochim. Acta, 2010, 98, 215-219.

12 R. Koivula, R. Harjula and H. Manni, EP2243547A1, 2010.

13 S. Starschich, T. Schenk, U. Schroeder and U. Boettger, Appl. Phys. Lett., 2017, 110, 182905.

14 J. Luo, X. Luo, J. Crittenden, J. Qu, Y. Bai, Y. Peng and J. Li, Environ. Sci. Technol., 2015, 49, 11115-11124.

15 Y. Zhao, Y. Tang, Y. Guo and X. Bao, Fibers Polym., 2010, 11, 1119-1122.

16 H. Cui, Q. Li, S. Gao and J. K. Shang, J. Ind. Eng. Chem., 2012, 18, 1418-1427.

17 H. Cui, Y. Su, Q. Li, S. Gao and J. K. Shang, Water Res., 2013, 47, 6258-6268.

18 Z. Shi, J. Ju, Y. Liang, W. Huang, W. Kang and B. Cheng, Chem. Lett., 2017, 46, 131-134.

19 H. Liu, B. Liu, X. Wang, L. Zhu, C. Feng, G. Zhang and D. Xu, J. Sol-Gel Sci. Technol., 2015, 76, 482-491.

20 M. Pokorny, V. Rassushin, L. Wolfova and V. Velebny, Polym. Eng. Sci., 2016, 56, 932-938.

21 Y. Su, W. Yang, W. Sun, Q. Li and J. K. Shang, Chem. Eng. J., 2015, 268, 270-279.

22 M. Filella, N. Belzile and Y. Chen, Earth-Sci. Rev., 2002, 57, 125-176.

23 S. C. Wilson, P. V. Lockwood, P. M. Ashley and M. Tighe, Environ. Pollut., 2010, 158, 1169-1181.

24 USEPA, National Primary Drinking Water Regulations, 2009.

25 Council of the European Union, Council Directive 98/83/EC of 3 November 1998 on the quality of water intended for human consumption, 1998.

26 X. Li, X. Dou and J. Li, J. Environ. Sci., 2012, 24, 1197-1203. 27 G. Ungureanu, S. Santos, R. Boaventura and C. Botelho, J. Environ. Manage., 2015, 151, 326-342.

28 B. Sargar, M. Rajmane and M. Anuse, J. Serb. Chem. Soc., 2004, 69, 283-298.

29 X. Guo, Z. Wu and M. He, Water Res., 2009, 43, 4327-4335.

30 Y. Zhu, M. Wu, N. Gao, W. Chu, N. An, Q. Wang and S. Wang, J. Hazard. Mater., 2018, 341, 36-45.

31 M. E. H. Bergmann and A. S. Koparal, J. Hazard. Mater., 2011, 196, 59-65.

32 Z. Qi, T. P. Joshi, R. Liu, Y. Li, H. Liu and J. Qu, J. Hazard. Mater., 2018, 343, 36-48.

33 M. Arnold, P. Kangas, A. Mäkinen, E. Lakay, N. Isomäki, G. Laven, M. Gericke, P. Pajuniemi, T. Kaartinen and L. Wendling, Mine Water Environ., 2019, 38, 431-446.

34 J. Li, X. Li, T. Hayat, A. Alsaedi and C. Chen, ACS Sustainable Chem. Eng., 2017, 5, 11496-11503. 
35 B. K. Biswas, J. Inoue, H. Kawakita, K. Ohto and K. Inoue, J. Hazard. Mater., 2009, 172, 721-728.

36 J. Holopainen and M. Ritala, J. Eur. Ceram. Soc., 2016, 36, 3219-3224.

37 W. A. Caliebe, V. Murzin, A. Kalinko and M. Görlitz, AIP Conf. Proc., 2019, 2054, 060031.

38 S. Ardizzone and C. Bianchi, J. Electroanal. Chem., 1999, 465, 136-141.

39 V. G. Deshmane and Y. G. Adewuyi, Microporous Mesoporous Mater., 2012, 148, 88-100.

40 Y. Du, P. Yang, Z. Mou, N. Hua and L. Jiang, J. Appl. Polym. Sci., 2006, 99, 23-26.

41 R. Ruiz-Rosas, J. Bedia, J. M. Rosas, M. Lallave, I. G. Loscertales, J. Rodriguez-Mirasol and T. Cordero, Catal. Today, 2012, 187, 77-87.

42 Z. Yu, C. Xu, K. Yuan, X. Gan, C. Feng, X. Wang, L. Zhu, G. Zhang and D. Xu, J. Hazard. Mater., 2018, 346, 82-92.

43 M. Alvarez and M. Torralvo, Colloids Surf., A, 1994, 83, 175182.

44 V. Reddy, D. Hwang and J. Lee, Korean J. Chem. Eng., 2003, 20, 1026-1029.

45 W. Xia, F. Wang, X. Mu and K. Chen, Fuel Process. Technol., 2017, 166, 140-145.

46 J. Y. Koo, S. Hwang, M. Ahn, M. Choi, D. Byun and W. Lee, J. Am. Ceram. Soc., 2016, 99, 3146-3150.

47 Y. Sun, J. Qu, Q. Guo, J. Song, G. Wei, X. Xi, G. Hou and T. Qi, Ceram. Int., 2017, 43, 12551-12556.
48 H. Wang, Y. Duan and W. Zhong, ACS Appl. Mater. Interfaces, 2015, 7, 26414-26420.

49 J. Blackwell and P. Carr, J. Liq. Chromatogr., 1991, 14, 28752889.

50 S. Muhammad, S. T. Hussain, M. Waseem, A. Naeem, J. Hussain and M. T. Jan, Iran. J. Sci. Technol., Trans. A: Sci., 2012, 36, 481-486.

51 D. Konrad, Ion exchangers, De Gruyter, Berlin, 1991.

52 S. Goldberg and C. Johnston, J. Colloid Interface Sci., 2001, 234, 204-216.

53 R. Liu, W. Xu, Z. He, H. Lan, H. Liu, J. Qu and T. Prasai, Chemosphere, 2015, 138, 616-624.

54 M. E. Essington and M. A. Stewart, Soil Sci. Soc. Am. J., 2016, 80, 1197-1207.

55 C. Dai, Z. Zhou, X. Zhou and Y. Zhang, Water, Air, Soil Pollut., 2014, 225, 1799.

56 P. Dorjee, D. Arnarasiriwardena and B. Xing, Microchem. J., 2014, 116, 15-23.

57 J. Simonin, Chem. Eng. J., 2016, 300, 254-263.

58 Y. Ho and G. McKay, Process Biochem., 1999, 34, 451-465.

59 D. Robati, J. Nanostruct. Chem., 2013, 3, 55.

60 Y. Ho and G. McKay, Process Saf. Environ. Prot., 1998, 76, 332-340.

61 J. Febrianto, A. N. Kosasih, J. Sunarso, Y. Ju, N. Indraswati and S. Ismadji, J. Hazard. Mater., 2009, 162, 616-645.

62 K. Y. Foo and B. H. Hameed, Chem. Eng. J., 2010, 156, 2-10. 